\section{Factores de riesgo asociados al virus de inmunodeficiencia humana en hombres privados de su libertad en Mérida, Yucatán, México}

\author{
Roberto De Anda, Rosa E. Suárez, Ligia Vera, \\ Carlos Castro y María del R. González
}

Risk factors associated with human immunodeficiency virus in men deprived of their liberty in Merida, Yucatan, Mexico

A case control study was conducted to know risk factors associated to HIV infection in Yucatan, Mexico jails. Repeated imprisonment, having more than eleven intercourses couples and having sex with other men were statistically related to HIV infection. Tattooing and intravenous drugs abuse were no significant risk factors.

Key words: Prisons, HIV, risk factors, Mexico.

Palabras clave: Prisiones, VIH, factores de riesgo, México.

$\mathrm{E}$ n México, al igual que el resto del mundo, la epidemia ocasionada por el virus de la inmunodeficiencia humana $(\mathrm{VIH})$ ha tenido repercusiones profundas en los individuos y los sistemas de salud. La incidencia nacional acumulada de casos de SIDA de 1983 al 31 de diciembre de 2011 fue de 148.130 pacientes; en el mismo período, para el Estado de Yucatán fue de 3.598 casos $^{1}$.

Se considera que los sujetos privados de su libertad son un grupo particularmente vulnerable a contraer esta infección por que viven en un espacio en el que se presentan diversas prácticas de riesgo; sin embargo, a pesar de su importancia epidemiológica no ha sido suficientemente estudiado. En este trabajo se identificaron los factores de riesgo asociados a la infección por VIH en la población masculina recluida en los Centros de Readaptación Social (CERESO) del Estado de Yucatán.

Se realizó un estudio de casos y controles, que incluyó 26 casos y 104 controles. El grupo de casos se conformó con todos los internos que al momento del estudio tenían diagnóstico de VIH/SIDA; el grupo control se conformó con internos negativos en la prueba de tamizaje para detección de anticuerpos contra VIH (Determine de Laboratorios Abbott $\left.{ }^{\circledR}\right)$, al momento del estudio. La información sobre factores de riesgo se obtuvo por medio de un instrumento que recaba información sociodemográfica, prácticas sexuales fuera y dentro del CERESO, presencia de tatuajes y uso de drogas intravenosas. Se estimaron los Odds ratio e intervalos de confianza de $95 \%$ con modelos multivariados de regresión.
Las variables asociadas a la infección fueron: ser reincidente en el penal $(\mathrm{p}=0,003 ; \mathrm{OR}=18,03 ; \mathrm{IC} 95 \%: 2,6-124,6)$, haber tenido más de 11 parejas sexuales en toda su vida $(\mathrm{p}=0,003$; OR $=14,67$; IC95\% 2,4-86,7) y tener parejas sexuales masculinas dentro del Centro de Readaptación Social ( $\mathrm{p}$ $=0,000 ;$ OR $=75,9$ IC95\%11,8-488,4).

Contrariamente a lo esperado, en nuestro estudio los tatuajes y el uso de drogas intravenosas no fueron factor de riesgo en la población estudiada, a diferencia de lo reportado por otros autores ${ }^{2}$.

El haber tenido más de un ingreso al penal es una variable que ha sido reportada por otros autores como factor de riesgo ${ }^{3}$, lo cual se corrobora con nuestros resultados, ya que el ser reincidente fue una de las variables que resultaron ser factores de riesgo.

Uno de los aportes del trabajo es el análisis de las prácticas sexuales antes y durante su estancia en la prisión de manera independiente; se pudo determinar que las relaciones sexuales de hombres con hombres dentro y fuera de estos centros de rehabilitación eran un factor de riesgo para adquirir la infección.

El hecho de que dos de las tres variables que se asociaron a la infección estén directamente ligadas al ingreso o prácticas dentro de los CERESOS, es una evidencia más de la importancia que tienen las prisiones como espacios de riesgo. Es importante considerar que lo que sucede en términos de salud dentro de los penales tiene impacto en la población general, especialmente en infecciones de transmisión sexual; ya que las visitas conyugales son una vía por la que las infecciones adquiridas dentro de las prisiones cruzan sus muros. Por lo que no ha de olvidarse que todo el esfuerzo que se realicen en los CERESOS para disminuir las infecciones de transmisión sexual, tendrá un impacto en la sociedad y se multiplicarán los beneficios.

Agradecimientos. Agradecemos el apoyo recibido de las autoridades del Centro de Readaptación Social de Yucatán, para poder llevar a cabo este trabajo.

\section{Referencias bibliográficas}

1.- Vigilancia Epidemiológica de casos de VIH/SIDA en México. Registro Nacional de Casos de SIDA. Actualización al 31 de diciembre de 2011 (CENSIDA). Disponible en: http://www.censida.salud.gob.mx/ descargas/2011/casos_acumulados_marzo2011.pdf (Consultado el 26 de abril de 2012).

2.- Sabin K M, Frey R L, Horsley R, Geby S M. Characteristic and trends of newly identified HIV infections among incarcerated populations: CDC HIV voluntary counseling testing, and referral system, 1992-1998. J Urban Health 2001; 78: 241-55.

3.- Troya M, Vila B. Infección por el virus de inmunodeficiencia humana y conductas de riesgo asociadas en un centro penitenciario de Montevideo, Uruguay. Rev Esp Sanid Penit 2010; 12: 21-8.

Universidad Autónoma de Yucatán, México.

Centro de Investigaciones Regionales "Dr. Hideyo Noguchi" (RdA. RES, LV, MdRG)

Facultad de Medicina (CC).

No existe conflicto de intereses

Trabajo financiado por CENSIDA, en el año de 2006, con el número de folio 0049.

Recibido: 24 de septiembre de 2012 / Aceptado: 23 de octubre de 2012

Correspondencia a:

María del Refugio González Losa.

glosa@uady.mx, refgon58@gmail.com 